\title{
Circulating Immune Complex Measurement
}

National Cancer Institute

\section{Source}

National Cancer Institute. Circulating Immune Complex Measurement. NCI Thesaurus.

Code $C 127611$

The determination of the amount of circulating immune complexes present in a sample. 